\title{
Trends of HIV/AIDS Infection in Arsi Zone from 2002- 2008 E.C (2010 to 2016 G.C), Oromia Region Ethiopia: Evidence from VCT Registry
}

Mesfin Segni Tafa ( $\square$ mesfintafa2011@gmail.com )

Arsi University College of Health Sciences https://orcid.org/0000-0001-5082-484X

Hailu Fekadu

Martha Aseffa

Hirpo Teno

Research

Keywords: HIV/AIDS, Ethiopia, Arsi Zone, VCT

Posted Date: July 2nd, 2020

DOI: https://doi.org/10.21203/rs.3.rs-38252/v1

License: (a) (i) This work is licensed under a Creative Commons Attribution 4.0 International License. Read Full License 


\section{Abstract}

Introduction: HIV continues to be a major global public health issue, having claimed more than 35 million lives so far. Globally, about 36.7 million people living with HIV currently, more than two third of the infection is the burden of Sub-Saharan Africa. Knowing the status of HIV/AIDS has the great value to individual health of treatment with ART and in terms of reductions in individual morbidity and mortality, and is equally costeffective. Therefore, the aim of this study was to assess trends and associated factor of HIV infection in Arsi zone from 2010 to 2016.

Methodology: A retrospective study was conducted in Arsi zone. Thirty health facilities (27 health centers and 3 Hospitals) were selected for the study from all woreda in the Zone. A total of 205,691 data was collected from VCT registration book. Data were entered into computer using Epi info 3.5.4 and exported for analysis to SPSS 21. Data were presented using tables and figures using line graphs. Logistic regression was used to see the association and significance was declared at P-value $<0.05$

Result: The study showed a total of 4300 HIV positive cases were reported between 2002(2009 G.C) to 2008(2016 G.C) according to available VCT registration book during survey at 30 health facilities. The trends of HIV of infection were not properly defined, it was 3.4\% in 2002(2010 G.C ) and mean while a gradual drop has been observed in the next five consecutive years, almost which was less than $2 \%$ prevalence and in 2008 the prevalence was raised to $2.4 \%$ compared to 2007 and before. The changes in HIV prevalence were uneven among districts. Findings from logistic regression analysis indicated that the fitted demographic characteristics like, marital status, age and occupation were significantly associated with HIV positivity in both bivariate and multivariate analysis.

Conclusion: There are no encouraging indications that the HIV prevalence has decreasing since there were variation among districts. Therefore there is a need of designing comprehensive strategy to combat the spread of HIV infections among all individuals. It is also important to strengthening VCT services at all level with strict follow up.

\section{Introduction}

The acquired immunodeficiency syndrome (AIDS) since its first recognition among five homosexual men in the United States, Los Angeles in 1981 and continually a major global Public Health issue, having claimed more than 35 million lives so far(1-3). The AIDS epidemic now ranks alongside the influenza pandemic of the early 1900s and the Bubonic plague of the 14th century in terms of fatalities(1).

Globally currently about 37.9 million people living with HIV, 1.7 million newly infected and 770,000 died from HIV at the end of 2018. Sub-Saharan Africa is the most affected region, with 25.6 (22.2-29.5) million people living with HIV in 2018. Also sub-Saharan Africa accounts for two-thirds of the global total of new HIV infections. Between 2000 and 2018, new HIV infections fell by 37\%, AIDS-related deaths fell by 45\% and 13.6 million lives saved $(3,4)$.

Declines in new HIV infections among adults have slowed alarmingly in recent years, with the estimated annual number of new infections among adults remaining nearly, static at about 1.9 million (1.7 million- 
2.2 million) in 2015. But there are different disparities across regions, within countries, between men and women and young and old, and among specific populations being left behind. These disparities must be addressed in order to achieve the reductions required to end the AIDS epidemic as a public health threat by 2030. Even though still the magnitude of HIV is high, the largest reduction in new adult HIV infections occurred in eastern and southern Africa. There were about 40000 fewer new adult HIV infections in the region in 2015 than in 2010, a 4\% decline. More gradual declines were achieved in the Asia and Pacifc region and western and central Africa. Rates of new adult HIV infections were relatively static in Latin America and the Caribbean, western and central Europe, North America and the Middle East and North Africa, while the annual numbers of new HIV infections in Eastern Europe and central Asia increased by 57\%(5).

Under Sustainable Development Goal 3, the global community has agreed to aim to end the AIDS epidemic by $2030(6)$, and under the UNAIDS "90-90-90" targets, countries work toward achieving, by 2020 , "90\% of people living with HIV knowing their HIV status; $90 \%$ of people who know their HIV-positive status on treatment; and $90 \%$ of people on treatment with suppressed viral loads(5).

AIDS is now affecting all sectors of Ethiopian society. The future course of the AIDS epidemic in Ethiopia depends on a number of factors including HIV/AIDS-related knowledge, social stigmatization, risk behavior modification, access to high-quality services for sexually transmitted infections (STIs), provision and uptake of HIV counseling and testing, and access to antiretroviral therapy $(A R T)(7,8)$.

The geographical structure of HIV epidemic is the consequence of drivers of the epidemic and the availability of susceptible population to the infection, strongest clustering has been observed in countries with a low national prevalence of HIV infection. The 'know your epidemic' concept recognizes this geographical feature as a key strategy in identifying populations at higher risk of HIV infection and in which prevention interventions should be targeted(9).

As with all generalized HIV/AIDS epidemics, heterosexual transmission is the primary mode of HIV transmission in the region and female commercial sex workers (CSW) remain a key population for HIV prevention efforts. Within Africa, the potential importance of men who have sex with men (MSM), in terms of enhanced HIV transmission among MSM sexual networks and 'bridging' into heterosexual sexual networks, is only now being recognized and MSM research remains in its infancy(10)..

The current moment is one of great optimism in HIV prevention. Breakthroughs in HIV treatment, prevention science, program implementation and human rights realization have led to assertions that "an AIDS free generation" is possible that Advances in HIV prevention(11).

The main drivers of the epidemic to explain the overall trends in the country have not been described. It is also not known whether the main transmission determinants differ by sex or differ between rural and urban areas. Understanding the direction of the change in HIV prevalence, along with various drivers of HIV transmission in different populations and areas of the country, is of paramount importance in intervention design, evaluation, and scale-up, [UNAIDS and WHO 2011].

The impact of HIV/AIDS on human suffering, cultures, demographics, economics, and even politics has been felt in nearly every society across worldwide. Monitoring a localized HIV/AIDS epidemic is important for more 
effective prevention strategies. In Ethiopia even though adult HIV prevalence has declined at the national level, little information is available about the sub geographic areas and certain subpopulation groups in the country. Majority of the individual studies conducted HIV/AIDS previously emphasis on prevalence and risk factor at a point time(), did not indicated the trend for many years HIV infection using large sample size. The finding of this study would indicate the past and current infection rate in Arsi Zone that might help program planners to design and integrated prevention and control strategies. Therefore, this study was intended to assess the trends and Associated factors of HIV infection in Arsi zone from VCT Registry from 2010 to 2016 in Ethiopia.

\section{Methods}

\section{Study setting}

The study was undertaken in Arsi Zone Oromiya regional state from May 2016 to October 2016. The zone shares boundaries with East Showa, West Hararghe, Bale and West Arsi Zones. Asella is the capital town of Arsi Zone, which is located $175 \mathrm{~km}$ South East of Addis Ababa capital of the country. Based on 2007 Housing and population census projection, the total population of Arsi is projected to be $3,280,667$ million in 2016 , of which $90 \%$ of the population is estimated to be rural residents. Administratively, the zone is divided into 25 , woredas and 2 administrative towns having an area of $23,679.7 \mathrm{~km}^{2}$.The average altitude ranges from 1700 to 4000 meters above sea level. The average temperature varies from 10 to $24^{\circ} \mathrm{C}$.

The 9 months report (from September to May 2008 E.C) about 209,876 people tested for HIV, of this 42,898 received testing from VCT service and 166,978 from PITC. Clients testing positive for HIV (at VCT) were 276, Clients testing positive for HIV (at PITC) were 351, Number of adults and children with HIV infection newly enrolled in Pre ART care were 444, Number of adults and children with advanced HIV infection ever started on ART were 4621 Number of adults and children who are currently on ART were 4034(Arsi Zone Health Department report 2016).

\section{Study design}

Health institutions based retrospective study design was employed to extract data from VCT registry.

\section{Study population}

All clients registered on VCT registry book from September 2002 to August 2008 from those selected health facilities (Health Center and Hospital) were included.

\section{Exclusion Criteria}

- Records that did not have complete information especially on the test result relevant for the study.

\section{Sample size and Sampling procedure:}

All participants with complete information from the registry book were included from September 2002 to August 2008 E.C. About, two hundred thousand six $(205,691)$ participants were included. From 100 health 
centers found in the woreda, 27 health centers (Health Centers located in the woreda town) and 3 Hospitals were selected purposively those giving ART and VCT services.. The majority of health centers found outside the district town were established recently ( $<5$ years) and they were not delivering ART service and have no organized VCT registration book during the assessment.

\section{Study Variables}

Dependent variable: HIV test result

Independent Variables: Age, sex, Occupation, marital status and Religion

\section{Data collection procedures and quality Assurance}

\section{Instrument(Questionnaires)}

Data collection format(checklist) was prepared to extract the necessary information for the study based on the VCT registration form of Federal Ministry of Health (FMOH). Thirty one (31) data collectors(community health counselors, Health Officers, Nurses and Midwifes who are working on the VCT were recruited. Pre arrangement was done by communicating with the respective health facility leader.

Data collectors were oriented how to fill the questioners from the registry. The completeness of the filled questionnaires were randomly selected and cross checked with the information VCT registry.

\section{Statistical Analysis}

The variables were coded and entered into computer using Epl info version 3.5.4 software by data clerk and then transported to SPSS version 21 software for Analysis. Data was Cleaned and checked for missing values, outliers and for any inconsistency before running the analysis. Descriptive statistics using frequency and percentage was used to describe the pattern of occurrence of HIV infection. Cross tabulation was done to see differences between different characteristics. Row total was taken to know percentage. Logistic regression was used to identify some of sociodemographic predictors of HIV infection and difference of HIV prevalence between Health facility. Odds ratio(OR) both Crude and Adjusted odds ratio with $95 \%$ confidence interval $(\mathrm{Cl})$ at P-value less than 0.005 was considered to declare significant association. After obtaining percentages using SPSS, Microsoft office Excels Worksheet on a window 2010 was used to show trends of HIV infection.

\section{Ethical consideration}

Support letter was obtained from Arsi University College of Health Sciences, Research and community service coordinator and submitted to respective health facilities. Since data were extracted from registry, no need of further informed consent from the participants since code was used to represent individual information in the registration book.

\section{Result}




\section{Socio-demographics Characteristics of the Respondents}

A total of 205,691 data were collected from the 30 selected facilities from available registry. The detail of information is presented below in Table 1. 
Table 1

Total participants visited health facility for VCT as collected from the registration book from 20022008 E.C (2010 to 2016 G.C)

\begin{tabular}{|c|c|c|c|c|c|c|c|c|}
\hline \multirow[t]{2}{*}{ Facility Name } & \multicolumn{7}{|l|}{ Year } & \multirow[t]{2}{*}{ Total } \\
\hline & 2002 & 2003 & 2004 & 2005 & 2006 & 2007 & 2008 & \\
\hline Asella Hospital & 7624 & 6532 & 4643 & 3527 & 3432 & 3767 & 1411 & 30936 \\
\hline Assela HC & 5505 & 6111 & 8261 & 9748 & 8036 & 8410 & 1997 & 48068 \\
\hline Abomsa Hospital & & 140 & 802 & 484 & 1070 & 772 & 612 & 3880 \\
\hline Shirka HC & - & - & 218 & 1508 & 1176 & 1356 & 1220 & 5478 \\
\hline Eteya HC & 1241 & 1008 & 0 & 297 & 463 & 864 & 172 & 4045 \\
\hline Bele HC & - & - & 394 & 138 & 145 & 119 & 131 & 927 \\
\hline Abajema HC & 4182 & 2151 & 1787 & 482 & 353 & 138 & 100 & 9193 \\
\hline Sire HC & 1182 & 763 & 826 & 587 & 734 & 1507 & 287 & 5886 \\
\hline Sagure $\mathrm{HC}$ & - & - & - & 142 & 861 & 617 & 172 & 1792 \\
\hline Abomsa HC & - & - & 668 & 1473 & 86 & 241 & 425 & 2893 \\
\hline Diksis HC & 1931 & - & 1774 & 324 & 258 & 312 & 196 & 4795 \\
\hline Arboye $\mathrm{HC}$ & - & - & 960 & 1394 & 453 & 1410 & 1625 & 5842 \\
\hline Bokoji HC & 3884 & 4495 & 2476 & 1048 & 463 & 991 & 960 & 14317 \\
\hline Dera HC & 1660 & 1447 & 2702 & 1635 & 2197 & 2881 & 2024 & 14546 \\
\hline Bokoji Hospital & & & & & & & 308 & 308 \\
\hline Siltana HC & - & - & 399 & 448 & 600 & 1344 & 60 & 2851 \\
\hline Robe $\mathrm{HC}$ & 81 & - & 2741 & 1618 & 0 & 690 & 157 & 5287 \\
\hline Meraro HC & 1591 & 310 & 1833 & 732 & 1246 & 760 & 169 & 6641 \\
\hline Robe Hospital & & & 1018 & 926 & 478 & 576 & 258 & 3256 \\
\hline Ticho HC & - & - & 644 & 300 & 107 & 170 & 70 & 1291 \\
\hline Kersa HC & 1411 & 1580 & 1233 & 831 & 515 & 271 & 433 & 6274 \\
\hline Kula HC & 215 & - & - & 660 & 89 & - & - & 964 \\
\hline Huruta HC & 360 & 562 & 1278 & 1036 & 816 & 634 & 423 & 5109 \\
\hline Ogolcho HC & - & - & - & - & - & 81 & 63 & 144 \\
\hline Aseko HC & - & - & 794 & 712 & - & - & - & 1506 \\
\hline
\end{tabular}

N.B: shaded part indicates the test not done 


\begin{tabular}{|c|c|c|c|c|c|c|c|c|}
\hline \multirow[t]{2}{*}{ Facility Name } & \multicolumn{7}{|l|}{ Year } & \multirow[t]{2}{*}{ Total } \\
\hline & 2002 & 2003 & 2004 & 2005 & 2006 & 2007 & 2008 & \\
\hline Gonde HC & - & - & - & 1816 & 1852 & 1788 & 473 & 5929 \\
\hline Chancho HC & - & - & - & - & 48 & 67 & 144 & 259 \\
\hline Chole HC & 688 & 270 & 834 & 124 & 462 & 212 & 463 & 3053 \\
\hline Seru HC & 41 & 947 & 850 & 1309 & 1339 & 561 & 249 & 5296 \\
\hline Adele HC & 1243 & - & 325 & 1524 & 1538 & 262 & 32 & 4924 \\
\hline Total & 32839 & 26317 & 37460 & 34823 & 28817 & 30801 & 14634 & 205691 \\
\hline
\end{tabular}

The mean age of the VCT attendants was $26.3 \pm 9.9$. Majority (57.1\%) of the participants found in the group of 35 to 49 years old. Fifty five percent were male participants. Concerning marital status, data was recorded only for 38,390 participants, of these participants, more than half of the participants (54.2\%) were single and about $40 \%$ of were married. More than three quarters of the participants were orthodox and $3346(22.6 \%)$ were Muslims (Table 2). 
Table 2

Socio-demographic characteristics of VCT attendants in Arsi Zone from 2008-2008 E.C (2010 to 2016 G.C).

\begin{tabular}{|lll|}
\hline Variable & Frequency & Percentage \\
\hline Age & & \\
\hline$<20$ & 53,141 & 25.8 \\
\hline $20-34$ & 117,494 & 57.1 \\
\hline $35-49$ & 26,940 & 13.1 \\
\hline $50-64$ & 6,628 & 3.2 \\
\hline$>=65$ & 1,488 & .7 \\
\hline Mean \pm SD & $26.3 \pm 9.9$ & \\
\hline Sex & & \\
\hline Male & 113034 & 55.0 \\
\hline Female & 92657 & 45.0 \\
\hline Marital Status & & \\
\hline Single & 20,994 & 54.2 \\
\hline Married & 15332 & 39.6 \\
\hline Widowed & 341 & 0.9 \\
\hline Divorced & 1504 & 3.9 \\
\hline Separated & 560 & 1.4 \\
\hline Religion & & \\
\hline Orthodox & 10073 & 68.0 \\
\hline Muslim & 3346 & 22.6 \\
\hline Protestant & 1329 & 9.0 \\
\hline Other & 69 & 0.5 \\
\hline Occupation & & \\
\hline Student & 14755 & 43.5 \\
\hline Employed & 2263 & 6.7 \\
\hline Farmer & 5305 & 15.6 \\
\hline Housewife & 3472 & 10.2 \\
\hline Merchant & 1467 & 4.3 \\
\hline
\end{tabular}




\begin{tabular}{|lll|}
\hline Variable & Frequency & Percentage \\
\hline Driver & 466 & 1.4 \\
\hline Daily Worker & 2121 & 6.3 \\
\hline CSW & 77 & .2 \\
\hline Other & 3991 & 11.8 \\
\hline
\end{tabular}

\section{Overall Trends of HIV infection in Arsi Zone}

As shown in Table 3 below, small numbers (14634) of participants were screened in 2008 and large numbers were screened in 2004 and in 2005.

Table 3

Overall Trends of HIV infection in Arsi Zone from 2002-2008 E.C (2010 to 2016G.C)

\begin{tabular}{|c|c|c|c|c|c|c|c|c|}
\hline & \multicolumn{7}{|l|}{ Year- } & \multirow[t]{2}{*}{ Total } \\
\hline & 2002 & 2003 & 2004 & 2005 & 2006 & 2007 & 2008 & \\
\hline $\begin{array}{l}\text { Total } \\
\text { tested }\end{array}$ & 32839 & 26317 & 37460 & 34823 & 28817 & 30801 & 14634 & 205691 \\
\hline Male & 18699 & 14097 & 20320 & 18906 & 16066 & 16882 & 8064 & 113034 \\
\hline Female & 14140 & 12220 & 17140 & 15917 & 12751 & 13919 & 6570 & 92657 \\
\hline $\begin{array}{l}\text { Total } \\
\text { HIV + }\end{array}$ & $1109(3.4)$ & $542(2.1)$ & $634(1.7)$ & $622(1.8)$ & $557(1.9)$ & $478(1.6)$ & $358(2.4)$ & $4300(2.1)$ \\
\hline
\end{tabular}

The prevalence of HIV was high (3.4\%) in 2002, mean while a gradual drop has been observed in the next five consecutive years, almost which was less than $2 \%$ prevalence and in 2008 the prevalence was raised to $2.4 \%$ compared to 2007 and before.

As depicted in the Fig. 1 above, the proportion of the overall trends of HIV showed that a moderate declining from 2002 to 2004 and was almost similar fashion in the next three consecutive years until 2006 and somewhat decreased in 2007 and raised in 2008.Overall, the incidence the infection is constant as observed in the figure.

\section{Trend of HIV/AIDs among by sex}

There was consistent discrepancy of trend of HIV infection with regard to sex. In general, the magnitude of the HIV infection was higher among females, which was more than $2 \%$ as the trend reflects (i.e. in 2002 (4.5\%), in 2003(2.6), in 2004(2.1\%)) as displayed in Table 4 and in Fig. 2 below. 
Table 4

Trends of HIV infection in Arsi Zone from 2002-2008 E.C ( 2010 to 2016 G.C)by sex

\begin{tabular}{|lllllllll|}
\hline & Year & & & & & \multicolumn{3}{c|}{ Total } \\
\cline { 2 - 7 } & $\mathbf{2 0 0 2}$ & 2003 & 2004 & 2005 & 2006 & 2007 & 2008 & \\
\hline $\begin{array}{l}\text { Total } \\
\text { HIV + }\end{array}$ & $1109(3.4)$ & $542(2.1)$ & $634(1.7)$ & $622(1.8)$ & $557(1.9)$ & $478(1.6)$ & $358(2.4)$ & $4300(2.1)$ \\
\hline Sex & & & & & & & & \\
\hline Male & $477(2.6)$ & $225(1.6)$ & $266(1.3)$ & $237(1.3)$ & $240(1.5)$ & $190(1.1)$ & $168(2.1)$ & $1803(1.6)$ \\
\hline Female & $632(4.5)$ & $317(2.6)$ & $368(2.1)$ & $385(2.4)$ & $317(2.5)$ & $288(2.1)$ & $190(2.9)$ & $2497(2.7)$ \\
\hline
\end{tabular}

\section{Trends of HIV/AIDS prevalence in relation to Age}

Comparing the trends of HIV infection by considering age, it shows inconstant prevalence of HIV infection. It dint show constantly decreasing for example for age group 35-49, the prevalence was in 2002 and decreased to $5.4 \%$ in $2003,3.8 \%$ in 2004 and slightly increased by $0.2 \%$ from immediate previous years and decreased by 0.4 in the next two years in 2006 and 2007 struck by $1.6 \%$ in 2008. But in the age group of 2034 , the prevalence was $3.6 \%$ in 2002 and decreased to $2.3 \%$ in 2003 it was dropped by half in 2004 and static magnitude was observed for three years which was $1.6 \%$. It is also substantial proportion of age above 64 were affected by the epidemic in the last seven years (Table 5).

Table 5

Trends of HIV infection in Arsi Zone from 2002-2008E.C (2010 to 2016 G.C) by Age

\begin{tabular}{|c|c|c|c|c|c|c|c|c|}
\hline & Year & & & & & & & Total \\
\hline & 2002 & 2003 & 2004 & 2005 & 2006 & 2007 & 2008 & \\
\hline $\begin{array}{l}\text { Total } \\
\text { HIV + }\end{array}$ & 1109(3.4) & $542(2.1)$ & 634(1.7) & $622(1.8)$ & $557(1.9)$ & $478(1.6)$ & $358(2.4)$ & $4300(2.1)$ \\
\hline $\begin{array}{l}\text { Age } \\
\text { group }\end{array}$ & & & & & & & & \\
\hline$<20$ & 179(1.7) & $79(0.8)$ & $58(0.6)$ & $73(0.9)$ & $72(1.2)$ & $47(0.8)$ & $51(1.9)$ & \\
\hline $\begin{array}{l}20- \\
34\end{array}$ & $604(3.6)$ & $295(2.3)$ & $349(1.6)$ & $322(1.60$ & $286(1.60$ & $244(1.3$ & $162(1.8)$ & \\
\hline $\begin{array}{l}35- \\
49\end{array}$ & $240(6.3)$ & $136(5.4)$ & $178(3.8)$ & $186(4.0)$ & $157(3.6)$ & $148(3.2)$ & $116(4.8)$ & \\
\hline $\begin{array}{l}50- \\
64\end{array}$ & $69(5.6)$ & $25(3.00$ & $42(3.7)$ & $37(3.5)$ & $31(3.6)$ & $35(3.5)$ & $21(4.1)$ & \\
\hline$>=65$ & $17(5.8)$ & $7(4.7)$ & $7(2.7)$ & $4(2.0)$ & $11(4.6)$ & $4(2.0)$ & $8(6.1)$ & \\
\hline
\end{tabular}

Figure 3 shows the pattern of HIV occurrence among VCT attendants in relation to age. The patterns in HIV incidence in various age-groups were not well defined, which showed a decreasing a among young ages until 
2007 and raised in 2008 and among older group the incidence as general high and showed a mixture of peak and down at different years but in all peaked in 2008.

\section{Association of HIV infection with Socio-demographic factors}

Socio-demographic characteristics like marital status, sex, occupation and age were included in bivariate and multiple logistic regressions to see the association with HIV/AIDS infection. All these characteristics showed that significantly associated with HIV infection in the bivariate analysis, meanwhile to control confounding effect all these variables were entered together in the multiple logistic regression they were also significantly associated.

With regard to gender relation with HIV infection, in this report females were more likely to be HIV positive than male (AOR $=1.42,95 \% \mathrm{Cl}=1.24,1.64)$. When we see marital status as independent factor, the risk of HIV infection was higher among formerly married (widowed/divorced/separated) $(A O R=2.43,95 \% \mathrm{Cl}=1.99,2.98)$ compared to single. Though the strength of association is moderate, the likelihood of HIV positive was 1.43 times more likely among currently married and in union compared to unmarried ones $(\mathrm{AOR}=1.43,95 \% \mathrm{Cl}=$ $1.21,1.70)$.

Occupation showed that an association with the HIV positivity. A significantly strong association of HIV positive was observed among commercial sex workers. The odds of acquiring HIV infection was more than 3 times more likely among commercial sex workers $(A O R=3.30,95 \% \mathrm{Cl}=1.52,7.16)$. There was also significantly association with daily workers and house wife; the risk of infection was two times higher among daily workers $(A O R=1.95,95 \% \mathrm{Cl}=1.52,2.50)$ and 1.6 times higher among housewife $(A O R=1.62,95 \% \mathrm{Cl}=$ $1.28,2.05)$.

The odds of being infected by HIV/AIDS infection was higher among older people compared to younger age group. Participants found in age above 35 were more than 3 times more likely to get HIV/AIDS compared to younger age group, the AOR with $95 \%$ is as following (age $35-49, \mathrm{AOR}=3.17,95 \% \mathrm{Cl}=2.49,4.02$ ); age $50-$ $64, \mathrm{AOR}=3.35,95 \% \mathrm{Cl}=2.43,4.63) ;$ age $>=65, \mathrm{AOR}=3.20,95 \% \mathrm{Cl}=1.78,5.77)($ Table 6$)$. 
Table 6

Association of HIV infection with some of Socio-demographic characteristics at Arsi Zone

\begin{tabular}{|c|c|c|c|c|}
\hline \multirow[t]{2}{*}{ Characteristics } & \multicolumn{2}{|l|}{ HIV test Result } & \multicolumn{2}{|l|}{ Odds Ratio } \\
\hline & Negative & Positive & COR95\%Cl & AOR95\%Cl \\
\hline \multicolumn{5}{|l|}{ Marital Status } \\
\hline Single & $20575(98.0 \%)$ & $419(2.0 \%)$ & 1 & 1 \\
\hline Married & $14755(96.2 \%)$ & $577(3.8 \%)$ & $1.92(1.70,2.20)$ & $1.43(1.21,1.70)$ \\
\hline $\begin{array}{l}\text { Widowed/divorced } \\
\text { /separate }\end{array}$ & 2178(90.6) & $227(9.4)$ & $5.12(4.33,6.05)$ & $2.43(1.99,2.98)$ \\
\hline \multicolumn{5}{|l|}{ Sex } \\
\hline Male & 111231(98.4) & $1803(1.6)$ & 1 & \\
\hline Female & $90160(97.3)$ & $2497(2.7)$ & $1.71(1.61,1.82)$ & $1.42(1.24,1.64)$ \\
\hline \multicolumn{5}{|l|}{ Occupation } \\
\hline Student & 14471(98.1) & $284(1.9)$ & $0.53(0.43,0.65)$ & $0.90(0.71,1.14)$ \\
\hline Employed & 2168(95.8) & $95(4.2)$ & $1.18(0.91,1.54)$ & $1.18(0.89,1.56)$ \\
\hline Farmer & 5083(95.8) & $222(4.2)$ & $1.18(0.95,1.46)$ & $1.08(0.86,1.36)$ \\
\hline Housewife & 3181(91.6) & 291(8.4) & $2.46(2.00,3.02)$ & $1.62(1.28,2.05)$ \\
\hline Merchant & 1403(95.6) & $64(4.4)$ & $1.23(0.91,1.66)$ & $1.04(0.75,1.44)$ \\
\hline Driver & $451(96.8)$ & $15(3.2)$ & $0.90(0.52,1.54)$ & $1.17(0.66,2.06)$ \\
\hline Daily Worker & 1979(93.3) & $142(6.7)$ & $1.93(1.52,2.45)$ & $1.95(1.52,2.50)$ \\
\hline CSW & 69(89.6) & $8(10.4)$ & $3.12(1.47,6.61)$ & $3.30(1.52,7.16)$ \\
\hline Other & $3848(96.4)$ & 143(3.6) & 1 & 1 \\
\hline \multicolumn{5}{|l|}{ Age Group } \\
\hline$<20$ & $52582(98.9)$ & $559(1.1)$ & 1 & 1 \\
\hline $20-34$ & 115232(98.1) & $2262(1.9)$ & $1.85(1.68,2.03)$ & $1.52(1.25,1.84)$ \\
\hline $35-49$ & 25779(95.1) & $1161(4.3)$ & $4.24(3.84,4.69)$ & $3.17(2.49,4.02)$ \\
\hline $50-64$ & $6368(96.1)$ & $260(3.9)$ & $3.84(3.31,4.46)$ & $3.35(2.43,4.63)$ \\
\hline$>64$ & 1430(96.1) & $58(3.9)$ & $3.82(2.90,5.03)$ & $3.20(1.78,5.77)$ \\
\hline
\end{tabular}

Facility (district) disparity of HIV infection in Arsi zone 
Logistic regression was performed to see facility (district) disparity of the prevalence of HIV infection taking Adele health center as reference. As displayed in table - below high prevalence was observed at the following facilities; Robe hospital $(\mathrm{P}$-value $=0.0001, \mathrm{OR}=10.55,95 \% \mathrm{Cl}=3.70 .2,15.85)$, Abomsa Hospital $(\mathrm{p}$ value $=0.0001, \mathrm{OR}=7.24,95 \% \mathrm{Cl}=4.80,10.94)$, Assela Hospital $(\mathrm{P}$-value $<0.0001, \mathrm{OR}=8.85,95 \% \mathrm{Cl}=$ 6.04,12.96), Bokoji Hospital ( $P$-value $=0.0001, \mathrm{OR}=7.99,95 \% \mathrm{Cl}=4.08,15.65)$, Bele health center $(\mathrm{P}$-value $=$ $0.0001, \mathrm{OR}=8.39,95 \% \mathrm{Cl}=5.14,13.71)$, Ogolcho Health center $((\mathrm{P}$-value $=0.0001, \mathrm{OR}=6.52,95 \% \mathrm{Cl}=$ 2.48,17.19), Eteya Health center $(P$-value $=0.0001, O R=5.74,95 \% \mathrm{Cl}=3.78,8.72)$, Dera Health center $(P$-value $=$ $0.0001, \mathrm{OR}=4.47,95 \% \mathrm{Cl}=3.02,6.62)$, Huruta Health center $(\mathrm{P}$-value $=0.0001, \mathrm{OR}=4.18,95 \% \mathrm{Cl}=2.74,6.36)$, Bokoji Health Center $(\mathrm{P}$-value $=0.0001, \mathrm{OR}=3.63,95 \% \mathrm{Cl}=2.44,5.40)$, Kersa health center $(\mathrm{P}$-value $=0.0001, \mathrm{OR}$ $=5.14,95 \% \mathrm{Cl}=3.42,7.73)$, Robe Health center $(\mathrm{P}$-value $=0.0001, \mathrm{OR}=3.26,95 \% \mathrm{Cl}=2.26,5.31)$, Aseko Health center $(P$-value $=0.0001, O R=3.31,95 \% \mathrm{Cl}=1.94,5.66)$, Assela Health center $(P$-value $<0.0001, O R=3.18$, $95 \% \mathrm{Cl}=2.16,4.66)$.

No significant difference was observed like Shirka Health Center, Abajema Health center, Meraro Health Center, Kula Health center, Gonde Health Center, Chanco Health Center and Cholle Health Center(Table 7). 
Table 7

The proportion of HIV infection among VCT attendants at specific facilities from 2002-2008 E.C (2010 to 2016 G.C) .

\begin{tabular}{|c|c|c|c|c|c|c|}
\hline \multirow[t]{2}{*}{ Facility Name } & \multicolumn{2}{|c|}{ HIV Test Result } & \multirow[t]{2}{*}{ P-value } & \multirow[t]{2}{*}{ Odds ratio } & \multicolumn{2}{|l|}{$95 \% \mathrm{Cl}$} \\
\hline & Negative & Positive & & & Lower & Upper \\
\hline Asella Hospital & 29497(95.3) & $1439(4.7)$ & .0001 & 8.85 & 6.04 & 12.96 \\
\hline Assela HC & $47241(98.3)$ & $827(1.7)$ & .0001 & 3.18 & 2.16 & 4.66 \\
\hline Abomsa Hospital & $3731(96.2)$ & 149(3.8) & .0001 & 7.24 & 4.80 & 10.94 \\
\hline Shirka HC & 5457(99.6) & $21(0.4)$ & .218 & .70 & .39 & 1.24 \\
\hline Eteya HC & $3921(96.9)$ & $124(3.1)$ & .0001 & 5.74 & 3.78 & 8.72 \\
\hline Bele HC & $886(95.6)$ & $41(4.4)$ & .0001 & 8.39 & 5.14 & 13.71 \\
\hline Abajema HC & 9139(99.4) & $54(0.6)$ & .770 & 1.07 & .67 & 1.70 \\
\hline Sire HC & $5826(99.0)$ & $60(1.0)$ & .007 & 1.87 & 1.18 & 2.95 \\
\hline Sagure HC & 1771(98.8) & $21(1.2)$ & .009 & 2.15 & 1.21 & 3.81 \\
\hline Abomsa HC & 2857(98.8) & $36(1.2)$ & .001 & 2.29 & 1.39 & 3.77 \\
\hline Diksis HC & 4720(98.4) & $75(1.6)$ & .0001 & 2.88 & 1.85 & 4.48 \\
\hline Arboye HC & $5821(99.6)$ & $21(0.4)$ & .146 & .65 & .37 & 1.16 \\
\hline Bokoji HC & 14036(98.0) & $281(2.0)$ & .0001 & 3.63 & 2.44 & 5.40 \\
\hline Dera HC & 14196(97.6) & $350(2.4)$ & .0001 & 4.47 & 3.02 & 6.62 \\
\hline Bokoji Hospital & 295(95.8) & $13(4.2)$ & .0001 & 7.99 & 4.08 & 15.65 \\
\hline Siltana HC & 2820(98.9) & $31(1.1)$ & .009 & 1.99 & 1.19 & 3.35 \\
\hline Robe HC & $5188(98.1)$ & $99(1.9)$ & .0001 & 3.46 & 2.26 & 5.31 \\
\hline Meraro HC & 6600(99.4) & $41(0.6)$ & .631 & 1.13 & .69 & 1.83 \\
\hline Robe Hospital & $3077(94.5)$ & $179(5.5)$ & .0001 & 10.55 & 7.02 & 15.85 \\
\hline Ticho HC & 1274(98.7) & $17(1.3)$ & .005 & 2.42 & 1.32 & 4.45 \\
\hline Kersa HC & 6101(97.2) & 173(2.8) & .0001 & 5.14 & 3.42 & 7.73 \\
\hline Kula HC & 955(99.1) & $9(0.9)$ & .165 & 1.71 & .80 & 3.65 \\
\hline Huruta HC & 4994(97.7) & $115(2.3)$ & .0001 & 4.18 & 2.74 & 6.36 \\
\hline Ogolcho HC & 139(96.5) & $5(3.5)$ & .0001 & 6.52 & 2.48 & 17.19 \\
\hline Aseko HC & 1479(98.2) & $27(1.8)$ & .0001 & 3.31 & 1.94 & 5.66 \\
\hline Gonde HC & 5902(99.5) & $28(0.5)$ & .578 & .86 & .51 & 1.46 \\
\hline
\end{tabular}




\begin{tabular}{|c|c|c|c|c|c|c|}
\hline \multirow[t]{2}{*}{ Facility Name } & \multicolumn{2}{|c|}{ HIV Test Result } & \multirow[t]{2}{*}{ P-value } & \multirow[t]{2}{*}{ Odds ratio } & \multicolumn{2}{|l|}{$95 \% \mathrm{Cl}$} \\
\hline & Negative & Positive & & & Lower & Upper \\
\hline Chancho HC & 255(98.5) & $4(1.5)$ & .053 & 2.85 & .99 & 8.19 \\
\hline Chole HC & 3035(99.4) & $18(0.6)$ & .811 & 1.08 & .59 & 1.96 \\
\hline Seru HC & 5281(99.7) & $15(0.3)$ & .040 & .52 & .27 & .97 \\
\hline Adele $\mathrm{HC}$ & $4897(99.5)$ & $27(0.5)$ & 000 & 1 (constant) & & \\
\hline
\end{tabular}

\section{Trends of HIV infection by specific Health facility (Area).}

Under this section, Analysis was performed to see trends of HIV infection at specific health facilities. We tried to categorized health centers with good record keeping and weak registration system (unviability of full registration book for some years).

\section{Facilities having data(Good data handling system) from 2002 to 2008 E.C (2010-2016 G.C)}

Assela Referal and Teaching Hospital, Assela Health Center, Dera Health Center, Kersa Health center, Sire Health Center, Abomsa Hospital, Robe Hospital, Seru Health Center, Chole Health Center, Bokoji Health Center, Huruta Health Center, Abomsa Hospital, Abajema Health Center, Meraro Health Center, Gonde Health Center, Bokoji Hospital. As displayed in the graphs in the majority of health facilities the incidence of HIV infection showed an increasing, except in few health facilities like Seru Health Center and Gonde Health Center where it reflected decreasing, and in the other facilities it indicated variable incidences, it peaks in some year and fall in the other years. Badly the incidence of the disease is increasing at facilities like Robe Hospital, Abomsa Hospital, Huruta Health Center and Kersa Health Center. More than $3 \%$ of prevalence is observed in Assela Referral and Teaching Hospital, Robe Hospital, Abomsa Hospital and Kersa Health Center. In opposite of these facilities, low incidence, which was almost a constant $0.6 \%$ was observed at Abajema Health center(Guna Woreda).

(Detailed trend for each facility is presented under supplementary document)

\section{Facilities with poor data handling system}

More than $50 \%$ of the sampled health facilities have some problem of handling the recoded data properly. Especially from the following Health Facilities, Ogolcho Health Center from Ziway dugda wored, Kula Health center from Sude Woreda, Chancho Health center from Gololcha Health Center, Aseko Health Center from Aseko Woreda have less three years data during the assessment. Health centers like Hamda Diksis, Adele Health center and Eteya health Center have no data for one year. Other health centers such as; Robe Health center, Bele Health center, Shirka Health center, Siltana Health Center, Sagure Health center, Ticho Health Center, Arboye Health center and Abomsa Health center have no data from 2 to 3 years.

High prevalence of the infection was seen at Eteya, Robe and Bele Health centers which was more $2 \%$ and in majority of facilities the epidemic curve showed a steady increasing, but in contrast of this at Sagure Health center, the incidence of HIV infection is decreasing. For detail, the information for each health facility is 
presented as follow separately in tables to show the magnitude of problem (under supplementary information).

\section{Discussion}

The spontaneous spread of the HIV is a worldwide health challenge since its discovery before three decades and has lasted a great devastating consequence on socio economic growth. Globally the pandemic of HIV is becoming lesser, but still there is a substantial effect of the diseases at different segment of population especially those living in developing country. In our country context, as general report there was a drastic fell of HIV infection, but still there is no individual report that reflect specific area intensively. There is also a problem of handling reports (data) properly for a long time for the area which will help to trace the magnitude of the problem when needed. The reason why we conducted this study was to see the trends of HIV infection among VCT attendants in Arsi zone from 2002 to 2008 E.C.

The Analysis showed that the prevalence of HIV/AIDS showed dropout when compared 2002 E.C (2009/10 G.C). However, the rate of decline was not constant, it sharply decreased from $3.4 \%$ in 2002 E.C to $2.1 \%$ in 2003 and to $1.7 \%$ in 2004 but it slightly raised in the next years by $0.1 \%$, i.e. in 2005 to $1.8 \%$, in 2006 to $1.9 \%$ and slightly decreased in 2007 to $1.6 \%$ and the incidence raised above $2 \%$ in 2008 . The global, regional and National reports also indicated that a decrease of the incidence of HIV/ infection. For example according a global report on HIV/AIDS by UNAIDS, there was large reduction the infection was observed in eastern and southern Africa(5). But in the study area prevalence is still high compared to the national findings as explained earlier.

As general there was a gradual decline of HIV infection, still there are disparities of the prevalence of HIV/AIDS among districts (health facilities), districts like Robe, Abomsa, Kersa, Dera, Assela, Eteya, Aseko, Huruta, Ziway dugda, Bokoj were considred as hot spot areas for the prevalence of HIV infection. According to report of UNAID 2016, globally the magnitude of HIV infection. showed a downfall, but there is country, regional differences(5).

Factors associated with HIV positive was assessed, accordingly in this study significant association was observed among marital status with HIV positivity. The risk of HIV infection was higher among formerly married (widowed/divorced/separated) $(\mathrm{AOR}=2.43,95 \% \mathrm{Cl}=1.99,2.98)$ compared to single. Though the strength of association is moderate, the likelihood of HIV positive was 1.43 times more likely among currently married and in union compared to unmarried ones $(A O R=1.43,95 \% \mathrm{Cl}=1.21,1.70)$. Consistent with this study the study conducted in Nairobi Kenya reported that, this risk of HIV/AIDS was higher among widowed compared to unmarried(12-14). The attribute could be due to, the reason for their divorce and separation could be one of the partner might be affected by HIV infection or He she might have risky behavior. Whilst for widow, the cause for the death of the former partner could be related with HIV/AIDS.

Our study also showed that married individuals were at risk of getting HIV infection compared to unmarried(15). The justification for this association could be spouses are likely to enter into relationships without knowledge of each other's HIV status or with no interest to know their self and spouses HIV status even after marriage. In other context married individuals are less likely to use HIV prevention strategies 
including condoms and HIV counseling and testing services, especially when one of the spouses is not faithful.

With regard to the effect gender on being HIV positive, in this study females were more likely to be HIV positive than their counterparts. This is in line with different studies conducted in Ethiopia $(16,17)$. Evidences reflecting that a range of factors contribute to the vulnerability of women to the HIV virus. Women are victims of discrimination in the economic, social and political life of the community which factors may directly or indirectly contribute to their exposure to HIV/ AIDS. Many of them are also subjected to different kinds of violence's including sexual violence, harmful traditional practices like female genital mutilations which increase their chance of HIV infection(18),nature of their reproductive biology that increase the retention of viruses in their body compared to men $(19,20)$.

Occupation showed that an association with the HIV positivity. A significantly strong association of HIV positive was observed among commercial sex workers.

The odds of acquiring HIV infection was more than 3 times more likely among prostitutes $(A O R=3.30,95 \% \mathrm{Cl}$ $=1.52,7.16)$. Similarly a study conducted in Uganda, reported that the prevalence of HIV AIDS was higher among Prostitutes(21). It is well understood that these group of population were more vulnerable for the infection due their nature of work, living by trading sex. There was also significantly association with daily workers and house wife; the risk of infection was two times higher among daily workers $(A O R=1.95,95 \% \mathrm{Cl}=$ $1.52,2.50)$ and 1.6 times higher among housewife $(A O R=1.62,95 \% \mathrm{Cl}=1.28,2.05)$.

Age has significant influence on the HIV infection, when we disaggregate the prevalence of HIV/AIDs among different age group, the odds of being infected by HIV/AIDS infection was higher among older people compared to younger age group. Participants found in age above 35 were more than 3 times more likely to get HIV/AIDS compared to younger age group, the AOR with $95 \%$ is as following (age $35-49, A O R=3.17$, $95 \% \mathrm{Cl}=2.49,4.02)$; age $50-64, \mathrm{AOR}=3.35,95 \% \mathrm{Cl}=2.43,4.63)$; age $>=65, \mathrm{AOR}=3.20,95 \% \mathrm{Cl}=1.78,5.77)$. This finding is consistent with previous studies conducted at different areas including in our country, where older groups were positive for HIV infections $(22,23)$. The proposition of this finding that the longer survival of people living with HIV and the ageing of the HIV + population. This is also pointed as that people visit health facility (seek screening) when they suspect their selves as being infected if they were contacted sexually with person pass away and be panic for screening. Other than this, other this when their health is disturbed after the consequence of advanced stage of HIV/AIDS, after long stay with infections.

One of the limitations of this study was not including, PMTCT/ ANC data which is one of the three methods of data used for assessing trends of HIV/infection, due to pre assessment of uavailability of fully recorded registration and to avoid some overlapping as possible. The trend did not indicate by rural and urban due to no information available in the registrations. In some cases case may be retested, but we have tried to ignore those individuals tested previously from the registrations. So, considering this limitations it is better to cautiously interpret this findings. Though the study has its own strengths; use of a large sample laboratoryconfirmed HIV serostatus records. It might be the first time in the study area as well as probably in the country and elsewhere as far as our knowledge. 
Therefore, the finding from this study will be used to as a source of information to governmental and nongovernmental policy makers to evaluate their programs.

\section{Conclusions}

This analysis showed that the trend of HIV infection in Arsi zone showed a slight decreasing before 2016 and moderately increased in 2016 even though the VCT was not fully provided due to shortage of Kits for test at national level. The incidence of HIV was high among older group population compared to the younger. The changes in HIV prevalence were variable in some districts. Findings from logistic regression analysis indicated that demographic characteristics like, marital status, age and occupation significantly associated with HIV positive, after controlling the confounding effect.

Based on the finding of this study, there are is no encouraging indications that the HIV prevalence has decreasing since there was variation among districts. Therefore there is a need of designing strategy to combat the spread of HIV infections, so we have forwarded the following recommendation for Arsi university, Zonal health department and woreda health offices, Ministry of Health and other concerned stakeholders with HIV program and related to tackle or to make zero prevalence of this public health importance issue as follow;

\section{- For Ethiopian Federal Ministry of Health;}

- Working with partners to improve the uptake of VCT services at all level.

- Strengthening the VCT services properly with close follow up of the activities being done.

- Improvement of the HMIS VCT registration book to include other important socio-demographic characteristics like marital status, educational status occupational status and others which are important comparison variables.

- Monitoring the epidemics of HIV in accordance with subpopulation segmentation and localized intervention programs would have a vital importance rather than using the national prevalence as the key monitoring variable.

- More prevention campaigns should be intended and carried out while matters arising

- with increasing access to HIV testing, counseling, ART and care should be accessed.

- UN and other Organizations Re-strengthening their funding and technical support for developing country like Ethiopia to run the programs of HIV/AIDS service, including VCT service uptake improvement.

- Designing fingerprint identifier, to avoid some overlapping to determine the true incidence to avoid some social desirability bias and lies during incase of re-testing.

\section{List Of Acronyms}

AIDS Acquired Immuno deficiency syndrome

ART Anti Retro Viral Treatment

CDC Center for disease prevention and control office 
E.C Ethiopian Calendar

EDHS Ethiopian Demographic Health Survey

EPHI Ethiopian Public Health Institute

FMOH Federal Ministry of Health

G.C Gregorian Calendar

HIV Human Immunodeficiency syndrome

VCT Voluntary counseling and testing

UNAIDS The Joint United Nations program on AIDS

WHO World Health Organizations

\section{Declarations}

\section{Acknowledgement}

Our special thanks go to Arsi University for its limited financial support for the project activity during field work. It's our great pleasure to appreciate data collectors and data clerk for their precious time investment for this project. Finally we thank Woreda health offices and health facility leaders for their cooperation.

\section{Authors' contributions}

MTS had substantial contribution; did conceptualization of the study, design, analysis and interpretation of the data as well as manuscript preparation. HF has made substantial contributions on the analysis and interpretation of data and participated in the critical review and editing of the manuscript drafts for scientific merit and depth. MA and HT have been involved in analysis, interpretation of data and revising it critically for important intellectual contents. All authors read and approved the final manuscript.

\section{Funding}

Limited fund was obtained from Arsi University.

\section{Availability of data and materials}

Additional detailed information and raw data will be shared upon request addressed to the corresponding author.

\section{Ethics approval and consent to participate}

The required data were collected after obtaining ethical clearance from Arsi University College of Health Science Ethical Review Committee. In addition support of letter was written to Arsi Zone Health Office to get 
permission then the zone wrote letter to respective districts to give support during data extraction.

\section{Consent for publication}

The Author declares that contributed in this work are aware of the fact and have agreed to be named in the manuscript. The Authors guarantees that the Work has not been previously published elsewhere. All authors read and approved the final manuscript and agreed to be accountable for all aspects of the work in ensuring that questions related to the accuracy or integrity of any part of the work are appropriately investigated and resolved.

\section{Competing interests}

The authors declare that they have no competing interests.

\section{References}

1. CDC.The Global HIV/AIDS pandemic. 2019.

2. UNAIDS. Global AIDS update 2019.

3. WHO. Fact Sheets On HIV/AIDS. 2019.

4. UNAIDS. Global HIV \& AIDS statistics - 2019 fact sheet. 2019.

5. UNAIDS.Global AIDS update. 2016.

6. UN. Transforming Our World: The2030 Agenda for Sustainable Development 2015.

7. Central Statistical Agency (CSA) [Ethiopia], Macro. al. Ethiopia Demographic and Health Survey 2011. Addis Ababa, Ethiopia, and Calverton, Maryland, USA: Central Statistical Agency and ICF Macro.; 2012.

8. Central Statistical Agency (CSA) [Ethiopia], Macro. al. 2012. Ethiopia Demographic and Health Survey 2015. Addis Ababa, Ethiopia, and Calverton, Maryland, USA: Central Statistical Agency and ICF Macro. 2016.

9. Cuadros DF, Awad SF, Abu-Raddad LJ. Mapping HIV clustering: a strategy for identifying populations at high risk of HIV infection in sub-Saharan Africa. . Int J Health Geogr 2013;12(28).

10. David AL. HIV/sexually transmitted infection epidemiology, management and control in the IUSTI Africa region: focus on sub-Saharan Africa Sex Transm Infect. 2011;87.

11. Chris Beyrer, Anna-Louise Crago, Linda-Gail Bekker e. An action agenda for HIV and sex worker. . Lancet. 2015;385(9964):287-301.

12. Brima N, Burns F, Fakoya I, Kargbo B, Conteh S, Copas A. Factors Associated with HIV Prevalence and HIV Testing in Sierra Leone: Findings from the 2008 Demographic Health Survey. PLoS ONE 2015;10(10).

13. Samson B.A, Richard I.O, Omokhudu I, Jennifer A, Augustine A. Marital Status and HIV Prevalence in Nigeria: Implications for Effective Prevention Programmes for Women. Advances in Infectious Diseases. 2013:210-21.

14. Oluch T.etal. Correlates of HIV Infection Among Sexually Active Adults in Kenya: A National PopulationBased Survey The Open AIDS Journal 2011;5:125-34. 
15. Mohamed BA, Mahfouz MS. Factors Associated with HIV/AIDS in Sudan. BioMed Research International. 2013;2013:1-6.

16. Rathavuth H, Vinod M, Pav G. Factors Associated with Prevalent HIV Infections among Ethiopian Adults: Further Analysis of the 2005 Ethiopia Demographic and Health Survey. Calverton, Maryland, USA: Macro International Inc. 2008.

17. Kibret G.D, Ferede A, Leshargie Ch.T, Wagnew F, Ketema D.K, Alebel A. Trends and spatial distributions of HIV prevalence in Ethiopia. Infectious Diseases of Poverty. 2019;8(90).

18. Merso F. Women and girls and HIV/AIDS in Ethiopia. 2017.

19. Gillespie S. Poverty, food insecurity, HIV vulnerability and the impacts of AIDS in sub- Saharan Africa. 2008.

20. Girum T, Wasie A, Lentiro K, Muktar E, Shumbej T, Difer M ea. Gender disparity in epidemiological trend of HIV/AIDS infection and treatment in Ethiopia. Arch Public Health. 2018;76(1):51.

21. John R. High HIV prevalence and associated factors in a remote community in the Rwenzori region of Western Uganda. . Infectious Disease Reports 2010; 2:e13. 2010.

22. Joel N, Robert G.C. HIV infection in older adults in sub-Saharan Africa: extrapolating prevalence from existing data Bull World Health Organ. 2010;88:847-53.

23. Lakew Y, Benedict S, Haile D. Social determinants of HIV infection, hotspot areas and subpopulation groups in Ethiopia: evidence from the National Demographic and Health Survey in 2011. BMJ Open 2015;5.

\section{Figures}

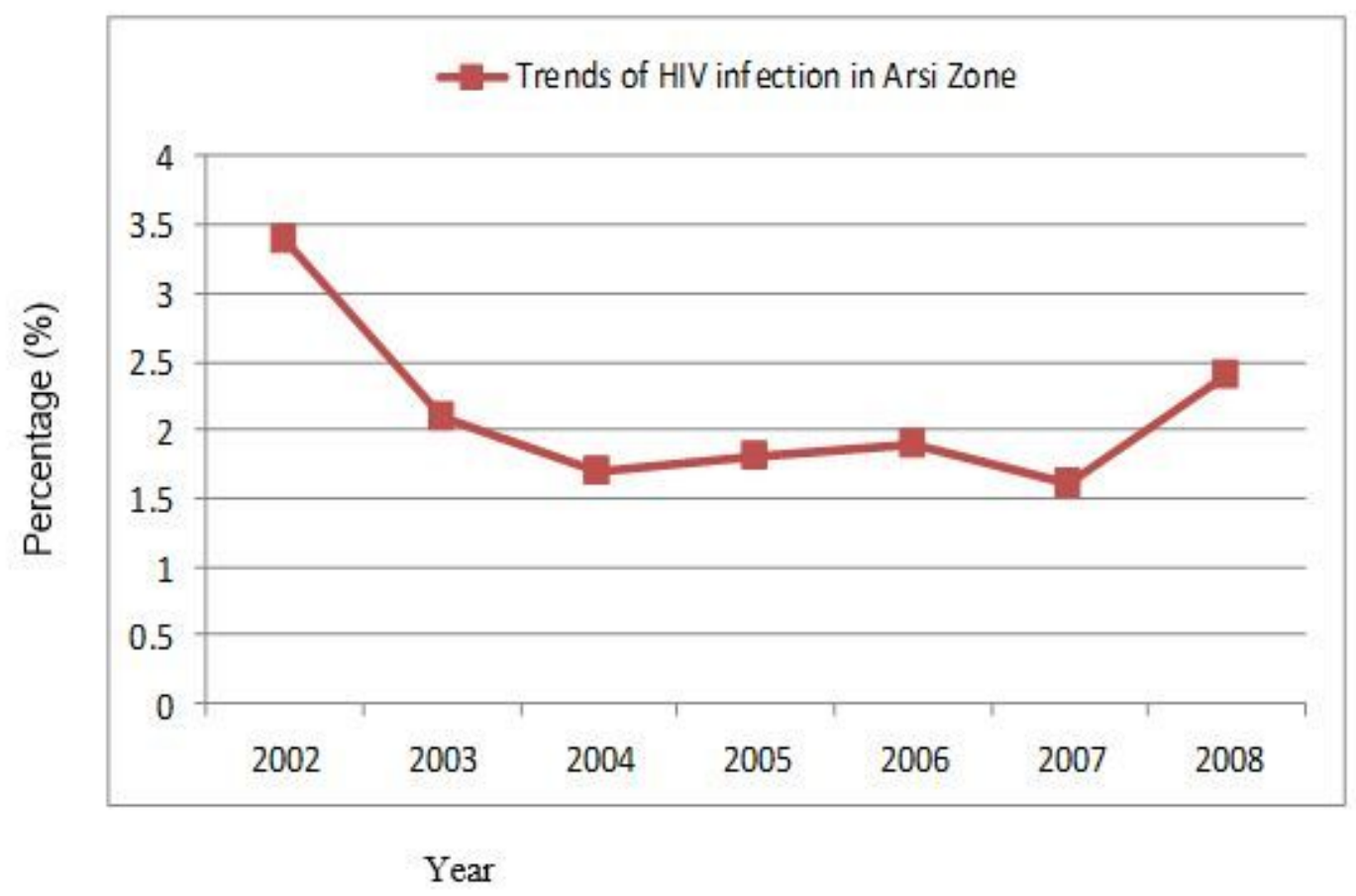




\section{Figure 1}

Trends of HIV infection among VCT attendants at Arsi Zone from 2002-2008 E.C (2010-2016)

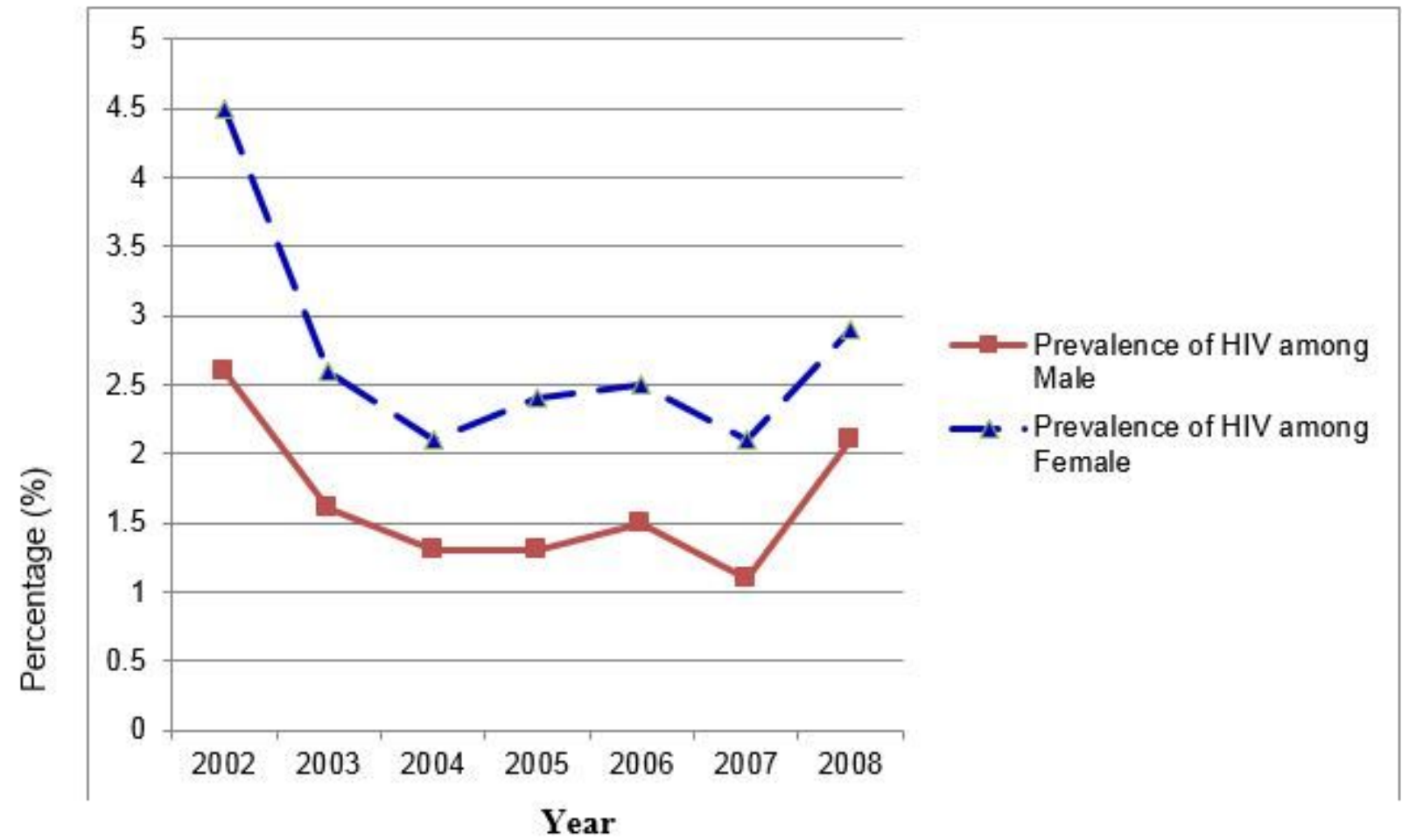

Figure 2

Trends of HIV infection among VCT attendants by Sex at Arsi Zone from 2002 to 2008 E.C (2010-2016 G.C). 


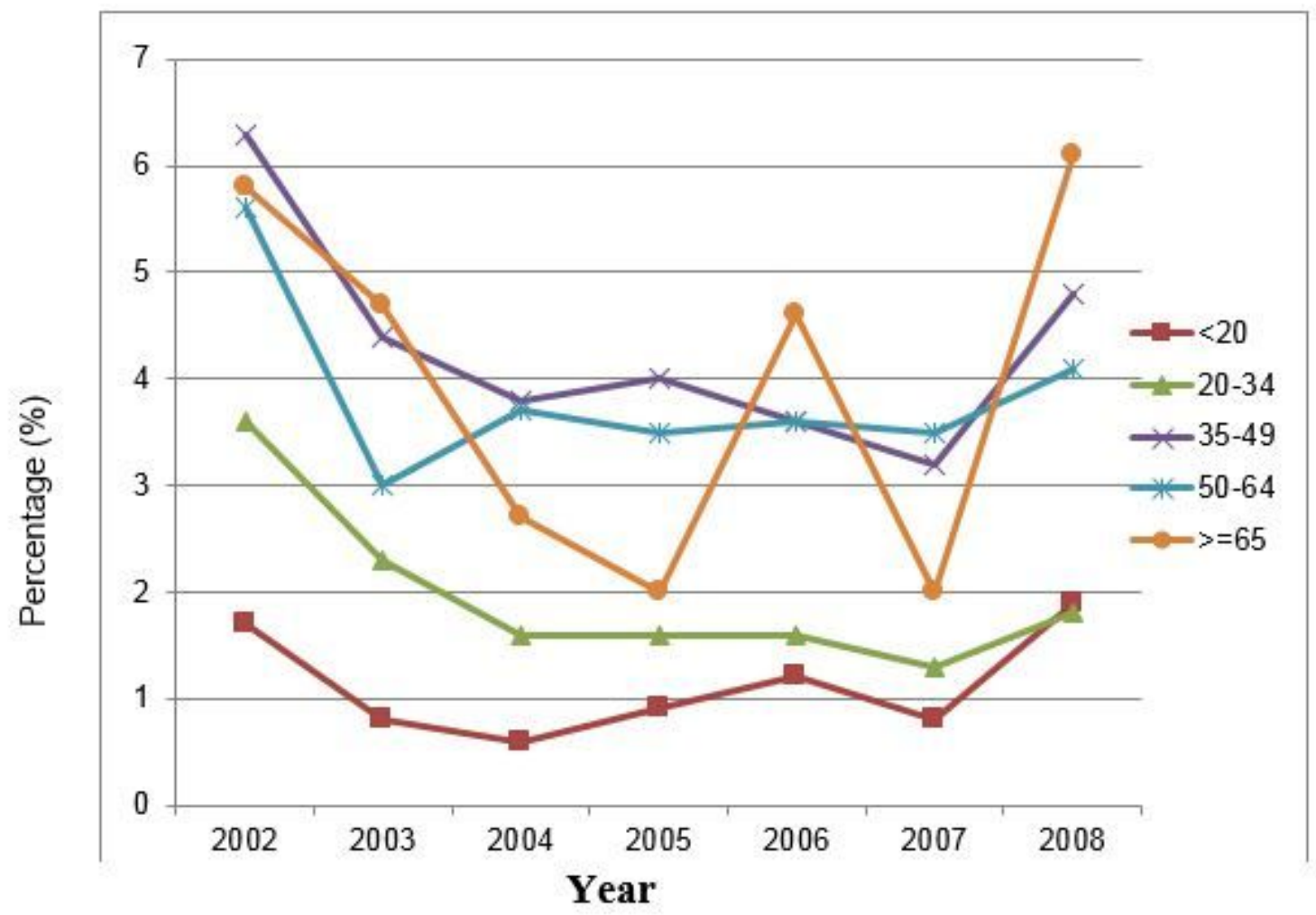

Figure 3

Trend of HIV/AIDS infection among Age groups at Arsi zone from 2002-2008 E.C (2010 to 2016 G.C)

\section{Supplementary Files}

This is a list of supplementary files associated with this preprint. Click to download.

- FacilityspecificTrendsupllementary.docx 